\title{
Supernumerary Teeth in Monozygotic Twins
}

\author{
Sohyun Kim, Young-Jin Kim, Hyun-Jung Kim, Soon-Hyeun Nam \\ Department of Pediatric Dentistry, School of Dentistry, Kyungpook National University
}

\begin{abstract}
Although the first case of supernumerary teeth had been documented almost 20 centuries ago, the etiology of supernumerary teeth still remains unclear. The prevalence of supernumerary teeth in the general Asian population is between $2.7 \%$ and $3.4 \%$. The pathogenesis of supernumerary teeth has been attributed to phylogenetic reversion(atavism), splitting of the tooth bud(dichotomy theory), locally induced hyperactivity of the dental lamina and a combination of genetic and environmental factors (unified etiologic explanation).

This report describes 3 cases of monozygotic twins with mesiodens who visited the pediatric dental clinic of Kyungpook national university hospital, and this is significant to support genetic factors involoved in the development of supernumerary teeth.
\end{abstract}

Key words : Supernumerary teeth, Genetic factor, Monozygotic twin

\section{I. 서 론}

과잉치는 정상 구조물에 부가적으로 나타나는 치아이다 ${ }^{1)}$. 유 치열과 영구치열 모두에서 보고되고 있으며 상악골 전치부에 호발하나 치열궁의 모든 부위에서 발생할 수 있다. 이런 과잉치 중 $\mathrm{Bolk}^{2)}$ 는 상악 정중부에 위치한 과잉치를 "mesiodens" 라 명 명하였고, 전체 과잉치의 $45 \sim 67 \%$ 를 차지하고 있다.

정중 과잉치는 발육 중인 치열에 영향을 미치는 가장 흔한 치 아 기형 중 하나이다. 인구 당 $0.15 \% \sim 1.0 \%$ 의 발병률을 보이 며 남성에서 여성보다 2 배 가량 호발하는 것으로 알려져 있다 ${ }^{3-5)}$.

정중 과잉치의 진단은 시진과 방사선 검사를 통하여 이루어 지며, 파노라마 사진과 상악 전방부 표준 방사선 사진이 이용된 다. 이런 상악 정중 과잉치는 맹출되거나 매복되어 인접 영구치 의 맹출 장애, 전위, 회전과 정중이개, 비강으로의 맹출, 낭종화 등 다양한 병발증을 야기하는데 특히 혼합 치열기에서는 인접 상악 영구치에 영향을 미쳐 맹출 지연, 부정교합 등을 나타낸다.

상악 정중 과잉치를 포함한 과잉치의 발생원인은 명확하게
밝혀지지는 않았으나 Osburne ${ }^{6}$ 은 격세유전설(atavism)에 의 해 발생한다고 하였고, Thoma근 정상치체가 분화되어 과증 식 활동에 의해 과잉치가 발생한다고 하였다. 또한 Sedano와 $G_{\text {Gorlin }}^{3)}$ 의 불완전 침투도에 의한 상염색체 우성 유전설과 유전 적인 요인과 환경적인 요인의 상호작용에 의한다는 설9)이 주장 되고 있다.

일란성 쌍생아의 출산율은 대개 $1 / 250$ 명 보고로 인종 등에 상관없이 비교적 일정한 편이며 쌍생아 간에는 동일한 유전자 형을 가지고 있다. 일란성 쌍생아는 성이 같고 외모 상 치아, 귀 모양이 같고, 머리 색깔, 결, 모양, 눈 색깔, 피부 색, 손, 발의 모양, 크기, 지문, 인체계측이 같으며 혈액형이 같게 된다.

일란성 쌍생아에서 관찰되는 과잉치는 그것이 유전적인 요인 에 의해 발생한다는 설을 뒷받침할 수 있다는 측면에서 흥미롭 지만, 현재까지 이에 대한 보고가 많지 않은 상태이다.

본 증례에서는 2005년에서 2011년까지 경북대학교 치과병 원 소아치과를 내원한 정중 과잉치를 가진 3 쌍의 일란성 쌍생 아를 보고하는 바이다.

Corresponding author : Soon-Hyeun Nam

Department of Pediatric Dentistry, School of Dentistry, Kyungpook National University, 2177 Dalgubeol-daero, Jung-gu, Daegu, 700-412, Korea

Tel: +82-53-600-7211 / Fax: +82-53-426-6608 / E-mail: shnam@knu.ac.kr

Received January 18, 2013 / Revised July 9, 2013 / Accepted July 24, 2013

※This research was supported by Kyungpook National University Research Fund, 2013. 


\section{II. 증례 보고}

\section{1. 증례 1}

4세 3개월 된 남자 일란성 쌍생아들이 치아 우식을 주소로 본원을 내원하였다. 환아들의 전신 병력 상 특이소견은 없었고 임상적 및 방사선 검사 시 상 - 하악 유구치부위에 전반적인 우 식증 및 상악 정중 과잉치가 관찰되었다. 파노라마 방사선 사 진상 쌍생아 $\mathrm{IA}$ 의 경우 정상 방향의 양측성 정중 과잉치가 미 맹출한 양측 상악 중절치의 치간 이개를 야기하고 있었고 쌍생 아 I B에서는 역위된 양측성 정중 과잉치가 미맹출한 상악 중 절치 치관부의 구개측에 존재하고 있음을 확인할 수 있었다 (Fig. 1). 치근단 방사선 사진을 통하여 쌍생아들에서 존재하는 두 개의 양측성 상악 정중 과잉치는 모두 원추형임을 확인할 수 있었다(Fig. 2). 쌍생아 I A의 경우 정기검진 약 1 년 경과 후 정중 과잉치가 맹출되었음을 확인한 다음 단순 발치술 시행하 였으며 쌍생아 I B의 경우 상악 중절치의 치근 발육 정도를 확 인하며 정기 검진 약 3 년 후 두 개의 정중 과잉치를 수술적으로 제거하였다.

\section{2. 증례 2}

7세 4개월 된 남자 일란성 쌍생아들이 개인치과의원에서 검 진 중 과잉치 치료를 위하여 본원으로 의뢰되었다. 환아들의 전 신 병력 상 특이소견 없었으며 임상 및 방사선 검사 상 매복된 정중과잉치가 관찰되었다(Fig. 3). 파노라마 방사선 사진 상 쌍 생아 $\mathbb{I A}$ 의 경우 미맹출한 상악 우측 중절치의 근심측에 순구 개측으로 수평 매복된 하나의 정중 과잉치가 보였고 특이할 만 한 것으로 상악 좌측 중절치의 설면에 Talon cusp이 관찰되었 다. 쌍생아 $\mathbb{I B}$ 의 경우 원심 변위된 미맹출 상악 우측 중절치의 근심 및 구개측에 정상 방향의 매복 과잉치와 상악 좌측 중절치 부위에 맹출 과잉치가 관찰되었다(Fig. 4). 쌍생아 $\mathbb{I I A}$ 의 경우 5 개월 후 수술적으로 정중 과잉치를 제거하였으며 쌍생아 $\mathbb{I B}$ 의 경우 초진 당일 상악 좌측 중절치 부위의 맹출 과잉치를 단 순 발치하였으며 5 개월 후 상악 우측 중절치 주위의 매복 과잉 치를 수술적으로 제거하였다.

\section{3. 증례 3}

7세 3개월 된 남자 일란성 쌍생아들이 정중 이개를 주소로 개인치과의원에서 의뢰되었다. 환아들의 전신 병력 상 특이소 견 없었으며 임상 및 방사선 검사 상 역위되어 매복된 2개의 정 중 과잉치가 관찰되었다(Fig. 5). 파노라마 방사선 사진 상 쌍 생아 III A과 쌍생아 $\mathbb{I I B}$ 모두 양측 상악 중절치 사이에 구개측 방향으로 역위된 두 개의 정중 과잉치가 관찰되었으며 쌍생아 $\mathbb{I I A}$ 에서 쌍생아 $\mathbb{I I B}$ 보다 다소 깊이 위치한 것을 확인할 수 있 었다(Fig. 6). 두 쌍생아 모두 한 달 뒤 매복된 두 개의 정중 과 잉치를 수술적으로 제거하였다.
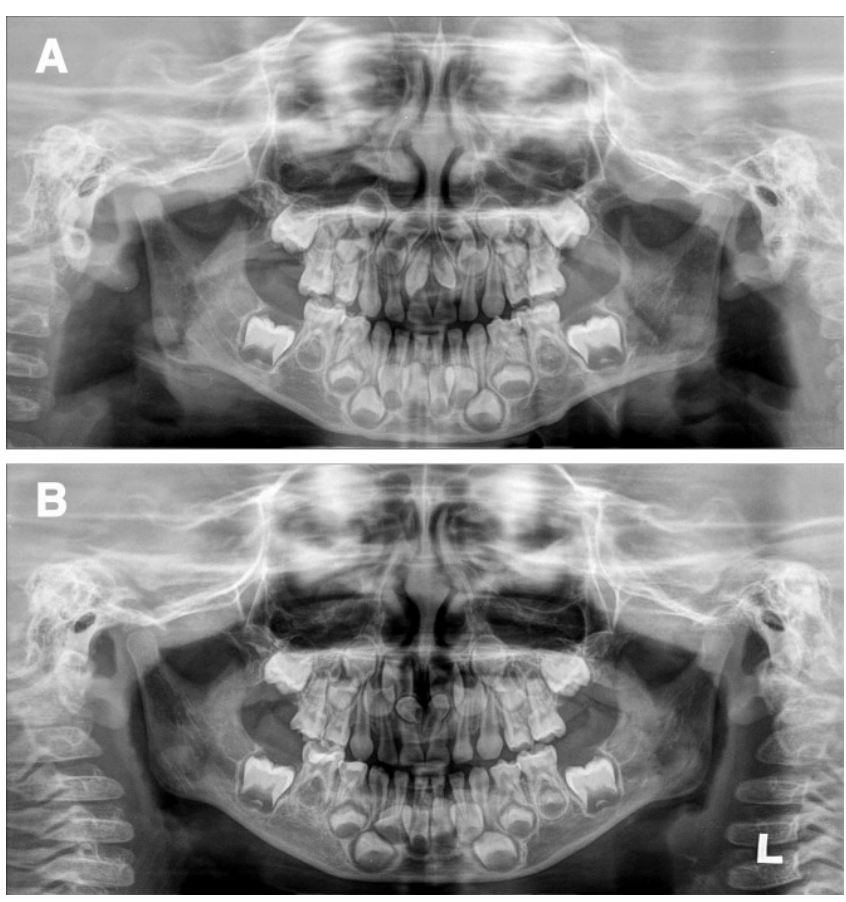

Fig. 1. Panoramic radiographs show bilateral mesiodentes in both twins of case 1. (A) Twin IA, (B) Twin IB.
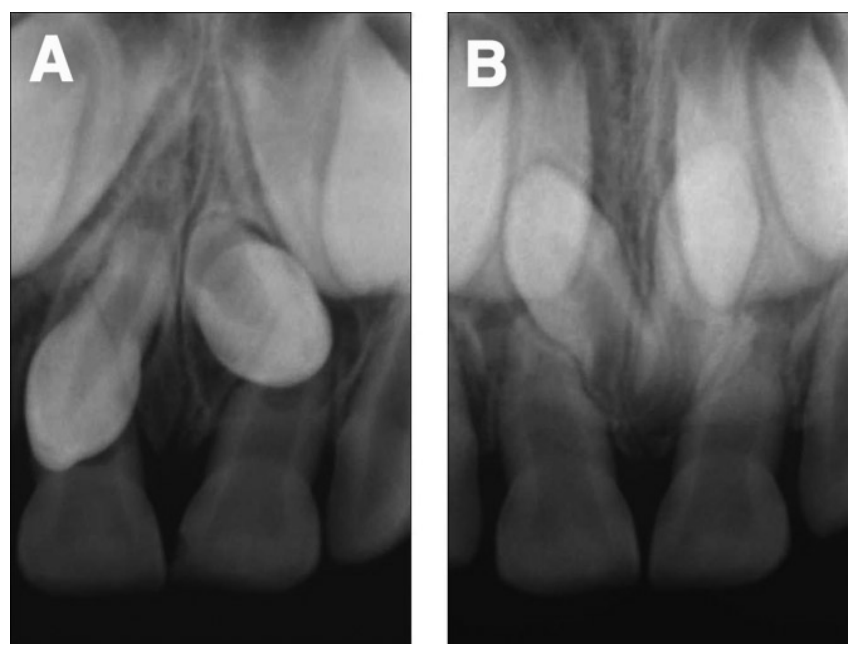

Fig. 2. Periapical radiographs at first visit. (A) Twin IA, (B) Twin IB.

4. 쌍생아간의 신체 성장발육상태 및 치아 발육단계에 대한 평가

개인의 키와 체중에 관한 정보는 그 사람의 성숙단계를 결정 하는 데 도움을 줄 수 있으며, 측정방법이 간단하므로 신체 성 장발육상태를 평가하는 데 유용하다. 본 증례보고에서는 쌍생 아들의 키와 체중을 비교하여 신체 성장발육상태를 평가해 보 았다. 또한 치아의 발육단계를 평가하기 위하여 파노라마 방사 선 사진 상에서 관찰되는 상, 하악 제 1 대구치의 석회화정도를 Nolla의 치아발육단계를 이용하여 평가하였다. 

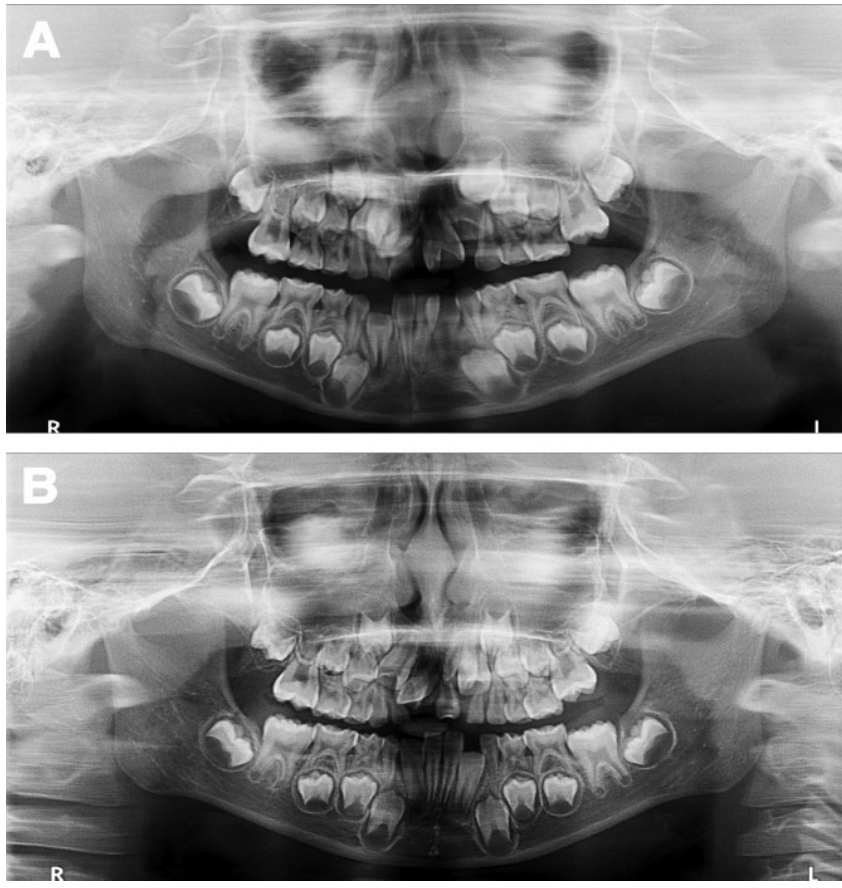

Fig. 3. Panoramic radiographs show mesiodens in both twins of case 2 . Twin IIA (A) has one mesiodens, whereas twin IIB (B) has two.

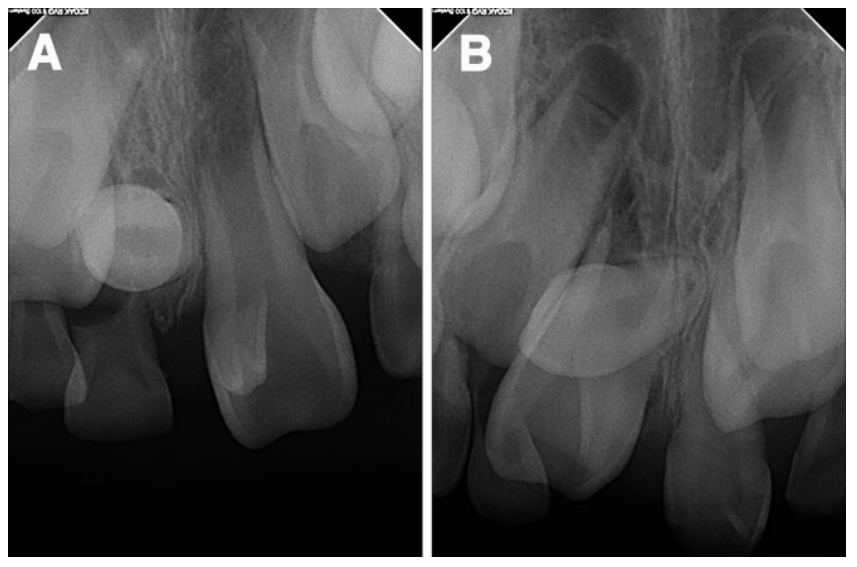

Fig. 4. Periapical radiographs at first visit of case 2. (A) Twin IIA, (B) Twin IIB.

Table 1. Age, sex, PMH and physical developmental status of monozygotic twins

\begin{tabular}{ccccc}
\hline Case & Patient & Age $/$ Sex & PMH & Height $/$ Weight \\
\hline 1 & Twin IA & $4 Y 3 \mathrm{M} /$ Male & N $/ \mathrm{S}$ & $105.3 \mathrm{~cm} / 20.0 \mathrm{~kg}$ \\
& Twin IB & $4 Y 3 \mathrm{M} /$ Male & N $/ \mathrm{S}$ & $105.0 \mathrm{~cm} / 18.9 \mathrm{~kg}$ \\
2 & Twin IIA & $7 \mathrm{Y} 4 \mathrm{M} /$ Male & N $/ \mathrm{S}$ & Not recorded \\
& Twin IIB & $7 \mathrm{Y} 4 \mathrm{M} /$ Male & N $/ \mathrm{S}$ & Not recorded \\
3 & Twin IIIA & $7 Y 3 \mathrm{M} /$ Male & N $/ \mathrm{S}$ & $116.2 \mathrm{~cm} / 23.5 \mathrm{~kg}$ \\
& Twin IIIB & $7 Y 3 \mathrm{M} /$ Male & N $/ \mathrm{S}$ & $116.4 \mathrm{~cm} / 23.1 \mathrm{~kg}$ \\
\hline
\end{tabular}

세 증례 모두에서 쌍생아간의 신체 성장발육상태 및 치아 발 육단계는 거의 일치하였으나 증례 2에서 쌍생아들의 키와 체중 은 기록되어 있지 않아 신체 성장발육상태를 비교 평가할 수 없 었다(Table 1,2).
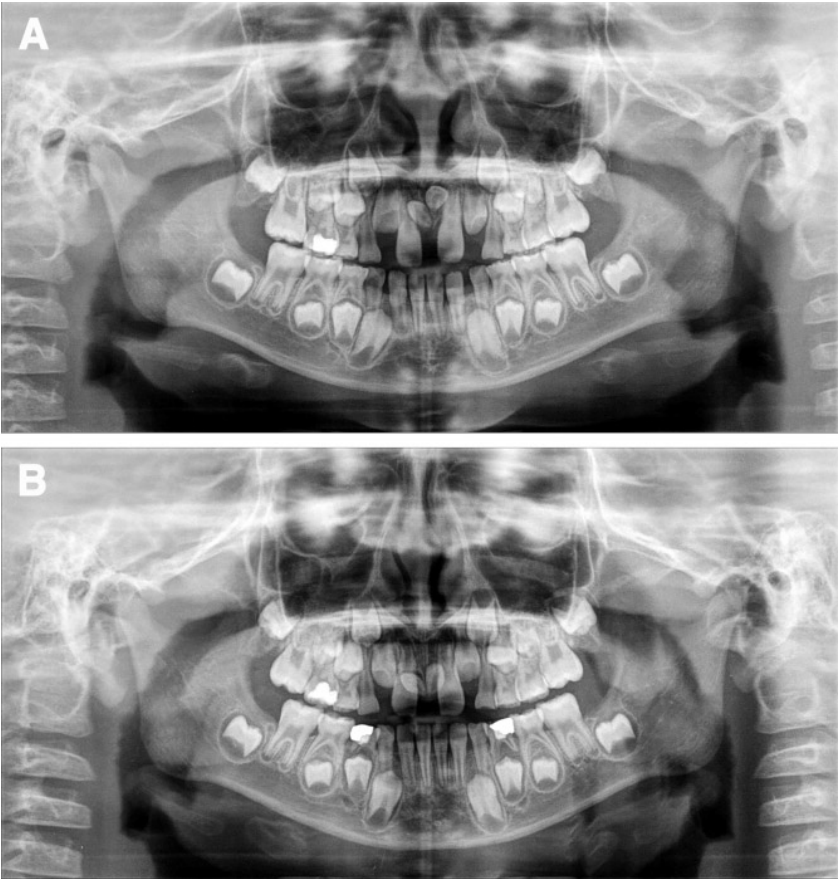

Fig. 5. Panoramic radiographs show bilateral mesiodentes in both twins of case 3. (A) Twin IIIA, (B) Twin IIIB.
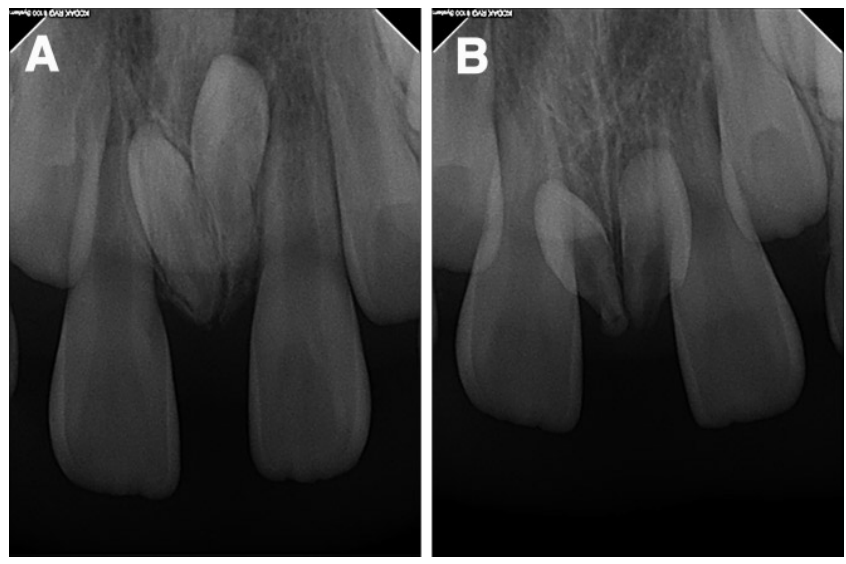

Fig. 6. Periapical radiographs at first visit of case 3. (A) Twin IIIA, (B) Twin IIIB.

Table 2. Tooth developmental stage of monozygotic twins

\begin{tabular}{|c|c|c|c|c|c|}
\hline Case & Patient & \multicolumn{2}{|c|}{ Tooth } & \multicolumn{2}{|c|}{ Nolla stage } \\
\hline \multirow{4}{*}{1} & \multirow{2}{*}{ Twin IA } & 6 & 6 & $6+$ & $6+$ \\
\hline & & 6 & 6 & 7 & 7 \\
\hline & \multirow{2}{*}{ Twin IB } & 6 & 6 & $6+$ & $6+$ \\
\hline & & 6 & 6 & 7 & 7 \\
\hline \multirow{4}{*}{2} & \multirow{2}{*}{ Twin IIA } & 6 & 6 & 6 & 6 \\
\hline & & 6 & 6 & 6 & 6 \\
\hline & \multirow{2}{*}{ Twin IIB } & 6 & 6 & 6 & 6 \\
\hline & & 6 & 6 & 6 & 6 \\
\hline \multirow{4}{*}{3} & \multirow{2}{*}{ Twin IIIA } & 6 & 6 & 6 & 6 \\
\hline & & 6 & 6 & 6 & 6 \\
\hline & \multirow{2}{*}{ Twin IIIB } & 6 & 6 & 6 & 6 \\
\hline & & 6 & 6 & 6 & 6 \\
\hline
\end{tabular}




\section{III. 총괄 및 고찰}

과잉치의 발생 원인은 여전히 명확하지 않으며 여러 가지 설 이 제안되고 있다. Osburne ${ }^{6}$ 의 격세유전설과 $\mathrm{Thoma}^{7}$ 의 정상 치제의 과증식 활동에 의한 설이 지배적이며, Sedano와 $G_{\text {Gorlin }}^{33}$ 의 불완전 침투도에 의한 상염색체 우성 유전설과 유전 적인 요인과 환경적인 요인의 상호작용에 의한다는 설9) 등이 있 다. 일란성 쌍생아에서 발생한 정중 과잉치는 드물게 보고된 바 있으며 그러한 증례들은 유전적인 원인에 의한 과잉치의 발생 을 뒷받침할 수 있음에 의미를 두고 있다. Choi 등시과 Seddon 등 ${ }^{11}$ 은 한 쌍의 일란성 쌍생아에서 발생한 양측성 상악 정중 과 잉치를 보고하며 이는 과잉치가 유전적인 요인에 의해 발생한 다는 설의 증거를 제공하는 의미를 가진다고 하였다. Langowska-Adamsczyk와 Karmanska ${ }^{12)}$ 는 한 쌍의 일란성 쌍생아에서 과잉치와 매복치가 비슷하게 위치함을 보고하고 이 는 이들의 발생 과정이 유전적인 요인에 의한 것이라 하였다. 본 증례보고에서는 치아 우식증 및 정중 과잉치를 주소로 내원 한 세 쌍의 일란성 쌍생아 모두에서 동시에 발생한 정중 과잉치 를 보고하였으며 이는 과잉치의 발생에 유전적인 요인이 작용 함을 뒷받침 할 수 있는 중요한 의미를 가진다고 할 수 있을 것 이다.

이전에 보고된 증례보고들에 의하면 일란성 쌍생아간에 발생 한 과잉치는 양측성보다는 거울상으로 나타나는 편측성 과잉치 가 주로 관찰되었다 ${ }^{10,11)}$. 거울상이란 쌍생아에서 존재하는 편측 성 과잉치가 정준선을 기준으로 서로 반대측에 존재하는 것을 말한다. Seddon 등1ㅡ은 이전에 보고한 증례들 중에서 편측성으 로 발생한 과잉치를 가지는 3 쌍의 일란성 쌍생아 모두에서 거 울상으로 관찰되었던 것을 확인하였다.13.14). 이번 증례보고에서 는 위의 경향이 나타나지 않았는데 이는 한 명의 쌍생아만 제외 한 모든 쌍생아에서 양측성으로 나타났기 때문이며 상대적으로 발생률이 낮은 양측성 정중 과잉치의 발생을 보고함으로써 그 들의 유전적인 요인을 더욱 강하게 뒷받침할 수 있다는 의미를 가질 것이다.

일란성 쌍생아간에도 외모적으로 미미한 차이가 있다는 것은 잘 알려져 있다 ${ }^{15}$. 일란성 쌍생아의 과잉치에 있어서도 그러한 차이가 보이는데 그들의 발생 유무보다는 주로 크기와 형태에 서의 변이가 보고되었다 ${ }^{11}$. 또한 Seddon 등1ㅡ은 일란성 쌍생아 에서 발생하는 정중 과잉치의 개수는 거의 일치하나 형태나 방 향에 있어서 미미한 차이를 보이는 것이 일반적이라고 하였다. 그에 반해 본 증례보고에서 관찰된 과잉치의 형태는 쌍생아 II
$\mathrm{B}$ 를 제외하고는 모두 원추형으로 나타나 대부분 일치하였다 (Table 3). 일반적으로 과잉치의 형태는 Rajab와 Hamdan ${ }^{16)}$ 의 보고에 의하면 원추형 $74.8 \%$, 결절형 $11.9 \%$, 부가형과 치 아종 형태를 각각 $6.9 \%$ 와 $6.4 \%$ 로 보고하였으며 국내에서는 최 등 ${ }^{17)}$ 이 원추형이 $80.6 \%$, 결절형이 $12.4 \%$, 부가형과 치아 종 형태가 $3.5 \%$ 인 것을 보고하였고, 김 18 은 원추형이 $56.8 \%$, 결절형이 $14.8 \%$ 로 발견된 것을 보고하였다. 과잉치의 형태는 원추형이 가장 많이 관찰되며 그에 비해 결절형은 드물게 관찰 된다. 그러므로 일란성 쌍생아간에 동시에 관찰되는 결절형태 의 과잉치는 유전적인 요인을 더욱 강하게 뒷받침할 수 있을 것 으로 생각된다.

Seddon 등1은 이전에 보고된 8개의 증례들과 그들이 보고 한 1 개의 증례를 통하여 일란성 쌍생아에서 발생하는 정중 과 잉치의 경우 과잉치의 개수는 거의 일치하는 것으로 보고하였 다. 본 증례보고에서 세 쌍의 일란성 쌍생아들 중 증례 1 과 증 례 3 의 경우에는 쌍생아간에 발생한 정중 과잉치의 수가 동일 하였으나 증례 2에서는 불일치하였다(Table 3). 쌍생아 II B는 상악 우측 중절치 부위에 존재하는 하나의 원추형의 매복 과잉 치와 상악 좌측 중절치 부위에 관찰된 절치형 과잉치가 보인 반 면 쌍생아 $\mathbb{I} \mathrm{A}$ 는 상악 우측 중절치 부위에서는 쌍생아 $\mathbb{I} \mathrm{B}$ 와 동일한 부위에 하나의 원추형 매복 과잉치가 관찰되었으나 상 악 좌측 중절치 부위에서는 과잉치가 관찰되지 않아 쌍생아 간 에 존재하는 과잉치의 수가 일치하지 않았다. 특이할 만한 점은 쌍생아 IIA에서 과잉치가 상악 우측 중절치 부위에서 하나만 존재하였으나 상악 좌측 중절치의 설측으로 Talon cusp이 관 찰되었다. Talon $\operatorname{cusp}^{19)}$ 의 발생 기전은 명확하지 않으나 유전 인자와 환경인자의 결합에 의해 발생된다고 알려져 왔으며 Mader ${ }^{19}$ 의 "two-tooth rule" 에 따르면 이러한 치아 기형은 정 상 치아와 과잉치의 융합에 의하여 발생될 수 있다고 하였다. Mader ${ }^{20}$ 의 "two-tooth rule" 과 관련지어 설명한다면 본 증례 2에서의 상악 좌측 중절치 Talon cusp는 상악 좌측 중절치 부 위에 과잉치가 존재하였을 가능성이 있을 것으로 생각된다.

본 증례보고에서 관찰된 세 쌍의 일란성 쌍생아들의 과잉치 는 발생, 위치, 형태 및 개수에서 거의 일치하는 것으로 나타났 으며 이는 과잉치 발생이 유전적인 요인에 의해 많은 영향을 받 은 것으로 생각된다. 그러나 Townsend 등21은 9쌍의 일란성 쌍생아에서 발견된 과잉치가 8쌍의 쌍생아에서 서로 불일치하 였으며 한 쌍의 쌍생아에서만 과잉치의 수와 위치가 일치하였 다고 하였다. 이에 대하여 Townsend 등 21) 은 일란성 쌍생아에 서 보이는 불일치나 미미한 차이는 치아 형성 부위에서 일어난

Table 3. Inter-twin distribution of mesiodens in monozygotic twins

\begin{tabular}{ccccccc}
\hline \multirow{2}{*}{ Case } & \multirow{2}{*}{ Zygosity and sex } & Right & Left & $\begin{array}{c}\text { Inter-twin distribution } \\
\text { of mesiodens }\end{array}$ & Right & Twin B \\
\hline 1 & Monozygous, male & Conical, erupted & Conical, erupted & Near concordant & Conical, unerupted & Conical, unerupted \\
2 & Monozygous, male & Conical, unerupted & - (Talon cusp) & Discordant & Conical, unerupted & Incisiform, erupted \\
3 & Monozygous, male & Conical, unerupted & Conical, unerupted & Concordant & Conical, unerupted & Conical, unerupted \\
\hline
\end{tabular}


국소적 후성적 사건일 것이라고 하였다.

많은 저자들이 과잉치의 유전적인 영향에 관심을 가져왔다. $\mathrm{Brook}^{9}$ 은 과잉치의 발생율은 전체 인구 대비하여 과잉치가 발 생한 가족 내에서의 발생율이 현저히 높다고 보고하였다. Langowska-Adamsczyk와 Karmanska ${ }^{16)}$ 는 일란성 쌍생아에 서 과잉치와 매복치가 비슷하게 위치함을 보고하고 이는 이들 의 발생 과정이 유전적인 요인에 의한 것이라 하였다. 이와 같 이 일란성 쌍생아간에 동일하게 발생하는 과잉치는 유전적인 요인이 주요한 원인임을 강하게 암시한다. 과잉치의 병인론을 보다 확실히 알기 위해서는 본 증례와 같은 보고들과 함께 유전 적인 연구가 필요할 것이다.

\section{IV. 요 약}

과잉치의 병인론은 여전히 불명확하며 많은 저자들이 유전적 인 요인이 중요하게 작용할 것이라고 제안하였다. 본 증례에서 는 3 쌍의 일란성 쌍생아에서 발생한 정중 과잉치를 임상적 및 방사선학적 검사를 통해 다음과 같은 사실을 얻었다. 첫 번째, 세 쌍의 일란성 쌍생아에서 발생한 정중 과잉치의 위치와 모양 은 모두 일치하였다. 두 번째, 세 쌍의 일란성 쌍생아에서 발생 한 정중 과잉치의 수는 거의 일치하였으나 증례 2 에서는 불일 치하였다. 세 번째, 세 쌍의 일란성 쌍생아에서 발생한 정중 과 잉치의 맹출 방향에 있어서는 조금의 불일치가 존재하였다. 그 럼에도 불구하고 본 증례보고에서 관찰된 세 쌍의 일란성 쌍생 아들에서 동시에 발생한 정중 과잉치는 과잉치의 유전적인 발 생 원인을 뒷받침함에 의의가 있다.

\section{References}

1. Schulze C : Developmental abnormalities of the teeth and jaws. Thoma's Oral Pathology, 6th ed. Vol. 1. CV Mosby Co., 112-122, 1971.

2. Weinberger BW : An introduction to the History of Dentistry. Mosby, 514, 1948.

3. Sedano HO, Gorlin RJ. : Familial occurrence of mesiodens. Oral Surg Oral Med Oral Pathol, 27: 360-361, 1969.

4. Shafer WG, Hine MK, Levy BM. : Developmental disturbances of oral and paraoral structures. A Textbook of Oral Pathology, 4th ed. Philadelphia, Saunders, 47-49, 1983.

5. Hattab FN, Yassin OM, Rawashdeh MA. : Sumpernumerary teeth : report of three cases and review of the literature. ASDC $J$ Dent Child, 61: 382-393, 1994.

6. Osburne JM : How to plan a Dental Fair. J Colo
Dent Assoc, 44:25-34, 1966.

7. Thoma GE : Case report : mesiodens. Dent Surv, 42:48-49, 1966.

8. Gysel C. : Mesiodentes familiales. Rev Belge Med Dent, 18:929-960, 1963.

9. Brook AH : A unifying aetiological explanation for anomalies of human tooth number and size. Arch Oral Biol, 29:373-378, 1984.

10. Choi WK, Chang RC, Chuang ST : Bilateral mesiodentes of identical twins - a case report. Zhonghua Ya Yi Xue Hui Za Zhi, 9:116-21, 1990.

11. Seddon RP, Johnstone SC, Smith PB. : Mesiodentes in twins : a case report and a review of the literature. Int J Paediatr Dent, 7:177-184, 1997.

12. Langowska-Adamsczyk H, Karmanska B. : Similar locations of impacted and supernumerary teeth in monozygotic twins : a report of 2 cases. Am $J$ Orthod Dentofacial Orthop, 119:67-70, 2001.

13. Hunstadbraten K. : Anomalien bei Zwilingen. Quintessenz, 16:71-72, 1965.

14. Carton A, Rees RT. : Mirror image dental anomalies in identical twins. Br Dent J, 162:193-194, 1987.

15. Rajab LD, Hamdan MA. : Supernumerary teeth : review of the literature and a survey of 152 cases. Int j Paediatr Dent. 12:244-254, 2002.

16. Lundstom A. : Tooth morphology as a basis for distinguishing monozygotic and dizygotic twins. Am J Hum Genet, 15:34-43, 1963.

17. Choi BJ, Lee YS, Kim SO, Lee JH : Study of invertly impacted supernumerary teeth in the midpalatal region using computerized tomography. $J$ Korean Acad Pediatr Dent, 30:363-372, 2003.

18. Kim JT : A study on the supernumerary teeth. $J$ Korean Acad Pediatr Dent, 12:1-5, 1985.

19. King NM, Tsai JS, Wong HM. : Morphological and numerical characteristics of the Southern Chinese dentitions. Part I : Anomalies in the permanent dentition. Open Anthropol J, 3:54-64, 2010.

20. Shankar AA. Koshy AV, Duggal DS, Dandekar RC. : Syndontia with talon cusp : A case report and review of literature. J Oral Maxillofac Pathol, 2:1659, 2011.

21. Townsend GC, Richards L, Hughes T, Pinkerton S. : Epigenetic influences may explain dental differences in monozygotic twin pairs. Aust Dent $J$, 50:95-100, 2005. 


\title{
국문초록
}

\section{일란성 쌍생아들에서 관찰된 과잉치}

\author{
김소현 · 김영진 · 김현정 · 남순현
}

경북대학교 치의학전문대학원 소아치과학교실

과잉치의 발생 원인 및 빈도, 치료 등 과잉치에 대한 많은 선학의 연구가 있었으나, 현재에 있어서도 과잉치의 발생 원인은 여전히 명확하지 않은 상태이다. 전체 인구에서 $0.15 \%$ 1.0\%의 발병률을 보이는 과잉치의 병인론으로는 계통발생학적 돌연변이(atavism), 치배분열론(dichotomy theory), 치아판의 국소적인 증식 그리고 유전 및 환경적 요인들의 조합 (unified etiologic explanation) 등이 있다.

동일한 수정란으로부터 생긴 쌍생아인 일란성 쌍생아는 유전학적으로 동일한 개체이다. 이들에게서 나타난 과잉치에 대한 보고는 과잉치의 병인론에 있어 유전적인 요인이 강하게 작용함을 뒷받침할 수 있다는 면에서 의미를 가진다.

본 연구에서는 경북대학교 치과병원 소아치과 외래를 내원한 3쌍의 일란성 쌍생아에서 나타난 과잉치를 관찰하였으며, 이는 유전적인 원인에 의한 과잉치의 발생을 뒷받침함에 의미가 있어 보고하는 바이다.

주요어: 과잉치, 일란성 쌍생아, 유전 